\section{The Frenophone.}

A NOVEL form of telephone receiver, called the Frenophone (Fig. I), the invention of Mr. S. G. Brown, has been exhibited recently at the Royal Society conversaziones and at the Exhibition of Scientific Apparatus held in connexion with the British Association meeting at Liverpool. Its chief feature is the amplification of weak signals to great loudness without loss of purity in the rendering. It is thus of especial value in wireless telephony, such as broadcasting, where singing and orchestral music must be faithfully reproduced without the sort of distortion associated with inferior gramophones.

This novel "loud speaker" depends for its operation upon the high degree of friction existing between a moving surface of optical glass and a pad of cork

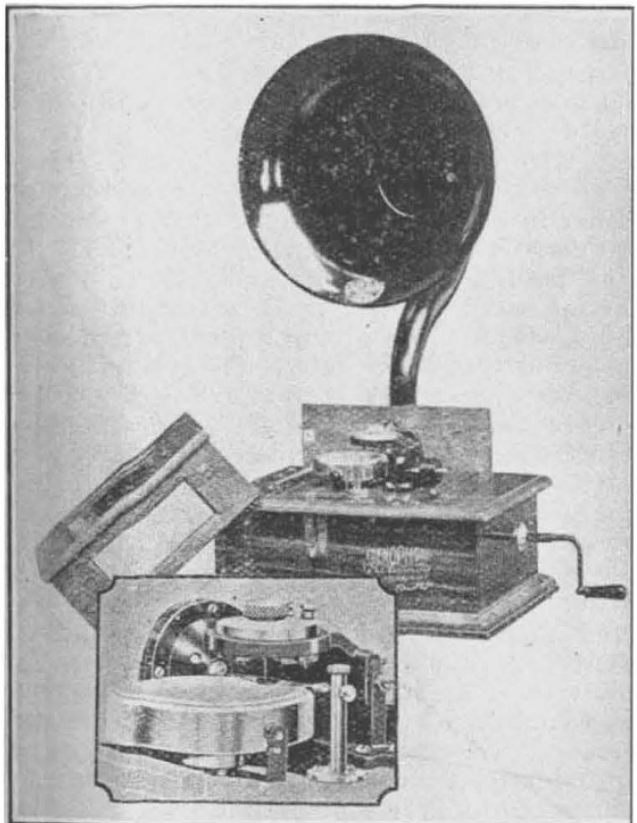

FIG. r.-The Frenophone. Inset, enlarged view of the revolving glass disk with cork friction pad.

or similar substance. The coefficient of friction, especially when the glass surface has been lightly treated with a tacky compound, is so high that very slight changes in a constantly applied pressure between the pad and glass produce enormous fluctuations in the tangential drag between them.

In practice, the glass surface is made in the form of a disk revolved slowly by a gramophone clock. The pad consists of a small steel disk faced with thin cork. The pad is laid upon the glass, its back being pressed upon by a light, flexible pin which, in turn, is fastened to the reed of a Brown telephone headpiece receiver. The pad is linked by " reins " to the diaphragm, which is of the usual loud-speaker type, and is fixed at the base of a trumpet.

Speech currents in the receiver coils actuate the reed, setting it in vibration. These vibrations, imparted to the pad, appear as oscillatory changes of the steady pressure of the pad on the glass disk. Corresponding large changes of the pull of the pad, by its reins, upon the diaphragm result in great amplification of the speech emitted from the trumpet. The great merit of the instrument, as compared with other forms of loud speaker, is the combination of loudness with purity; the sounds of the various musical instruments are individualised with absolute fidelity to the original.

$$
\text { NO. } 28 \text { I } 8 \text {, VOL. I } 12]
$$

\section{University and Educational Intelligence.}

Belfast.-Mr. R. W. Livingstone has been appointed vice-chancellor of the Queen's University. Mr. Livingstone, who is tutor and librarian of Corpus Christi College, Oxford, is the author of various publications in defence of classical education.

CAMBRIDGE.-Mr. E. W. Rice, junior, honorary chairman of the General Electric Company, Schenectady, New York, has sent on behalf of his board of directors " a check for five thousand dollars " to Sir Ernest Rutherford, to use to advance the work over which he presides. The gift to the Cavendish Laboratory is in appreciation of the debt which the General Electric Company owes to the Cavendish professor and his co-workers in scientific research. Mr. H. C. Levis, chairman of the British ThomsonHouston Company, has sent a cheque for $250 l$. for a similar purpose. These gifts will be used to supplement existing resources for research in the Cavendish Laboratory.

Mr. M. Dixon, Emmanuel College, has been appointed senior demonstrator in biochemistry.

GLASGow.-The subject for the essays to be sent in competition for the Thomson prize in geography for the session I923-4 is "Dwellings in Lands of Equatorial Climate: their Types, Materials, and Geographical Distribution." The competition is restricted to matriculated students of the university for the session 1923-4. The latest date for the receipt of essays is October 20, 1924. Each essay must be distinguished by two mottoes, accompanied by a sealed letter bearing on the outside the same mottoes, and containing a declaration subscribed by the author that the essay is entirely his own. They should be sent to the Clerk of the Senate.

London.-Mr. Geoffrey E. Duveen has given the sum of ro,oool. for the establishment of a University lectureship in otology.

The title of reader in plant ecology has been conferred on Dr. E. J. Salisbury of University College.

The following doctorates have been conferred: D.Sc. in Chemistry: Mr. R. Ray (University College), for a thesis entitled "Studies on Boron and Silica"; and E. W. J. Mardles, for a thesis entitled "A Contribution to the Theory of Colloidal Chemistry based on Studies in the Colloidal Chemistry of Cellulose Derivatives," and other papers. D.Sc. in Physics : Mr. H. P. Waran (University College), for a thesis entitled "Disintegration in Discharge Tubes." D.Sc. (Economics): Mr. H. Finer (London School of Economics), for a thesis entitled "Representative Government, and a Parliament of Industry."

MANChEster.-The following are among the persons on whom the new chancellor, the Earl of Crawford and Balcarres, will confer honorary degrees on the occasion of his installation on November Io : Mr. J. G. Adami, vice-chancellor of the University of Liverpool, Sir James G. Frazer, Sir Arthur Keith, and Sir Thomas H. Warren.

OxFORD.-By the recent death of Dr. A. Rambaut, the post of Radcliffe observer becomes vacant. It was in memory of Manuel Johnson, one of Dr. Rambaut's predecessors, that the Johnson memorial prize was founded. This prize is usually offered every four years for an essay on some astronomical or meteorological subject. It has been awarded this year to G. M. B. Dobson, Lincoln College.

The Burdett-Coutts scholarship in geology has been awarded to L. F. A. Edgell, University College.

The Halley lecture for I924 will be delivered by Prof. John Joly, professor of geology and mineralogy, Trinity College, Dublin. 
The University of King's College, Windsor, Nova Scotia, is to be moved to Halifax. A large part of its buildings was destroyed by fire in 1920, and its work has since been carried on with much difficulty in cramped and uncomfortable quarters. The Carnegie Corporation of New York will make a large grant towards the expenses of re-establishing the college at Halifax, where its work will be carried on in association with the University of Dalhousie. Its engineering courses will be discontinued.

In accordance with the terms of the will of the late Sir Archibald Dawnay, the Royal Institute of British Architects has awarded one scholarship of $50 l$. per annum to $\mathrm{Mr}$. R. W. Donaldson (University of Liverpool), and two scholarships of $25 l$. per annum each to Mr. R. H. Turner (University of Liverpool) and Mr. A. E. Cameron (Architectural Association). Mr. C. H. Hutton (University of Liverpool), who was awarded a scholarship of $25 l$. for $1922-1923$, has been granted a renewal of his scholarship for I923-I924. The scholarships are intended to foster the advanced study of construction and the improvement generally of constructional methods and materials and their influence on design.

A PRIZE fellowship of rooo Swedish kronor, offered for research in science by the Swedish Federation of University Women, has been awarded to an Englishwoman, Mrs. Muriel Wheldale Onslow. Mrs. Onslow is distinguished for her work on the biochemistry of plants. She has already been an " $\mathrm{N}$ " Fellow of Newnham College, Cambridge, and in I9I 5 was awarded a fellowship of the British Federation of University Women. The Swedish award proves that the work of British women in science is noteworthy not only in Great Britain but also in competition with that of other scientific workers, for the fellowship was open to the university women of eighteen countries.

A LIST of qualifications for teachers in technical schools recognised by the Burnham Committee for salary purposes as equivalent to a degree has been approved by the Board of Education, and has recently been issued as Appendix III. to the Report of the Standing Joint Committee on Salaries for Teachers in Technical Schools. (H.M. Stationery Office : Imperial House, Kingsway, London, W.C.2. I $d$. net. By post, $\mathrm{I} \frac{1}{2} d$.) In Section (c) Science and Technology the following qualifications are accepted :-(i.) Academic Qualifications: Associate of the Royal College of Science, London or Ireland, of the City and Guilds of London Institute, or of the Royal School of Mines; (ii.) Membership of Professional Societies: Associate membership of the Institutions of Civil Engineers, Mechanical Engineers, or Electrical Engineers, provided that the Associate Membership Examination has been passed, and that three years' engineering experience after the age of $2 I$ is reckoned as part of the qualification; associateship of the Institute of Chemistry, provided that the Institute's Examination for Associateship has been passed; and membership of the Pharmaceutical Society and Pharmaceutical Chemist, provided that the Qualifying and Major Examinations have been passed, and followed by three years' professional experience; (iii.) Miscellaneous: Whitworth scholarship if gained between I 887 and I922 ; and the first-class Colliery Managers' Certificate if the holder has three years' industrial experience after the age of $2 \mathrm{I}$, and has also obtained the diploma of a recognised mining college. This list may be modified from time to time, and qualifications not included can be submitted to the Board of Education by Local Authorities for approval.

\section{Societies and Academies.}

\section{PARIS.}

Academy of Sciences, October 8.-M. Albin Haller in the chair.-A. Lacroix: Notice on P. Elie Colin. The greater part of Colin's life was spent in Madagascar, where his work in geodesy, meteorology, and magnetism formed the foundation of all subsequent work in these subjects in the island.--Jean Perrin: Radio-chemistry of fluorescence. The theory developed in an earlier communication is modified to agree with the observation that in certain cases the fluorescent body may enter into chemical combination with the solvent (glycerol) or with oxygen. The influence of temperature on photo-chemical reactions is also investigated.-Ch. Depéret, F. Arcelin, and L. Mayet: The discovery of fossil remains of man of the Aurignacian age at Solutré (Saône-et-Loire). Three complete skeletors were discovered in positions which definitely prove burial. Drawings of the three skulls, with descriptions, are given. The men belonged to the Cro-Magnon race, Aurignacian period, but differ in some respects from the Cro-Magnons of Vézère and Grimaldi.-Alex. Véronnet: The formation of planetary systems and stellar systems.R. Fortrat and P. Dejean: An attempt to construct a bobbin without iron giving intense magnetic fields. The solenoid was constructed of wires of electrolytic copper, rectangular in section, cooled by a rapid current of water. The apparatus as made could carry a current of 4740 amperes and absorbed 277 kilowatts. A field of more than 40,000 gauss was obtainable.-Louis de Broglie: Quanta, the kinetic theory of gases and Fermat's principle.-L. P. Clerc : A question of photographic perspective.-Albert Portevin: Remarks concerning the relation between Young's modulus and the atomic volume. The equation expressing the relation between Young's modulus, the density and the atomic mass given in a recent communication by Th. Peczalski is identical with results arrived at by Fesserden in I 892. There is approximate agreement between the formula and experiment for certain metals, but for others, notably rhodium, tantalum, and tungsten, there are wide discrepancies, tungsten, for example, giving $42 \cdot 2$ as the modulus against 8.0 calculated.-P. Vaillant: The influence of small variations of temperature on the conductivity of solid salts and the rôle of the humidity in this phenomenon. The results of the experiments described lead to the conclusion that in solid salts the electrical conductivity is largely superficial and due to a particular condition of the surface layer. This accounts for the marked influence of traces of moisture on the observed conductivities. -V. Sorrel: Polarisation capacities with alternating currents.-Marc Bridel: Biochemical study on the composition of Monotropa hypopitys. Isolation of a new methyl salicylate glucoside, monotropitine. The extracts of this plant contain two glucosides, monotropeine and monotropitine, the latter being new : they are readily separated by their different solubilities in acetic ester. The new glucoside, monotropitine, has been isolated in the pure, crystalline state. Some physical and chemical properties are given: it does not appear to be identical with gaultherine.-René Wurmser: Energy yield and chlorophyll assimilation.-A. Maige: Remarks concerning the formation and digestion of starch in plant cells. The theory best in accord with known facts on the formation and digestion of starch in plants consists in regarding these two phenomena as due to entirely distinct catalytic actions.-G. Truffaut 